\title{
PENGEMBANGAN E-MODUL ANDROID BERBASIS METAKOGNISI SEBAGAI MEDIA PEMBELAJARAN BIOLOGI KELAS XII SMA/MA
}

\author{
Nukhbatul Bidayati Haka ${ }^{\text {a* }}$, Emilya Majid ${ }^{\mathrm{b}}$, Agus Pahrudin ${ }^{\mathrm{c}}$ \\ Email: nukhbatulbidayatihaka@radenintan.ac.id \\ $a^{*}, b, c$ Tadris Biologi, Universitas Islam Negeri Raden Intan Lampung, Lampung, Indonesia
}

\begin{abstract}
Abstrak
Tujuan penelitian ini adalah untuk mengembangkan e-modul android berbasis metakognisi serta menguji validitas, kepraktisan, dan efektivitasnya. Jenis penelitian ini adalah Research and Development (R \& D) model pengembangan Borg and Gall yang disederhanakan menjadi tujuh tahap yaitu, studi pendahuluan, perencanaan penelitian, pengembangan desain, uji coba terbatas, revisi uji coba terbatas, uji coba skala luas, revisi hasil uji coba secara luas. Sampel penelitian ini didapatkan melalui teknik purposive sampling yaitu 10 pesera didik pada uji coba skala terbatas dan 30 peserta didik pada uji coba skala luas. Uji kelayakan emodul android menggunakan angket validasi ahli media, ahli bahasa, ahli materi, serta angket respon dari pendidik dan peserta didik. Teknik analisis data menggunakan teknik deskriptif yang memaparkan hasil pengembangan produk E-modul Android Berbasis Metakognisi. Indikator metakognisi yaitu pengetahuan deklarasi, pengetahuan prosedural, dan pengetahuan kondisional. Hasil penelitian menunjukkan e-modul android berbasis metakognisi valid dan sangat layak, praktis, dan efektif dalam capaian metakognisi peserta didik sehingga dapat direkomendasikan dalam pembelajaran.
\end{abstract}

Kata Kunci: e-modul android, metakognis, media pembelajaran

\begin{abstract}
The purpose of this study is to develop an android e-module based on metacognition and investigate the validity, practicality, and effectiveness. The research design used Research and Development (R \& D) with Borg and Gall development model which is simplified into seven stages: preliminary study, research planning, design development, limited try out, limited try out revision, wide-scale try out, revision of the product and product's distribution. The sample selection used purposive sampling technique which consist of 10 students for limited try out and 30 students for wide-scale try out. The android e-module was developed and validated based on the questionnaire of media experts, linguists, material experts, teachers and students. The data were analysed by using descriptive technique that describes the results of Metacognition-Based Android E-module product development. Metacognition indicators were declarative knowledge, procedural knowledge, and conditional knowledge. The results sindicated that the metacognition-based android e-module was valid, realible, practical, and effective in improving students' metacognition and recommended in learning.
\end{abstract}

Keywords: android e-module, metacognition, learning media

71 I Universitas Raden Intan Lampung, Jl. Letnan Kolonel H Jl. Endro Suratmin, Kota Bandar Lampung, Lampung, Indonesia 


\section{PENDAHULUAN}

Pembelajaran dalam dunia pendidikan sekarang ini harus menyesuaikan dengan kubutuhan abad 21 yang menuntut manusia memiliki kemampuan belajar dan inovasi, media, informasi dan teknologi, serta kecakapan hidup (Fazriyah, 2016). Perkembangan teknologi pada abad 21 ini membuat manusia lebih berpikir kreatif serta memaksimalkan sistem yang telah ada (Fatoni \& Rendra, 2014) serta mengharuskan manusia untuk meningkatkan sumber dayanya (Subarkah, A. N. Qolbi, F.S. Irwansyah, W. Darmalaksa, 2017). Keadaan ini memiliki pengaruh besar dalam pendidikan di Indonesia (Pahrudin, 2019). Perkembangan teknologi di dunia pendidikan memberikan keringanan dalam proses pembelajaran baik untuk pendidik maupun peserta didik (Haka et al., 2020). Pada masa perkembangan teknologi dan informasi ini, penggunaan teknologi dan informasi merupakan salah satu pendekatan dalam belajar yang efektif dan dapat membantu guru dalam mendeverensiasi pengajaran yang dilakukan (Permani \& Priyanto, 2019). Salah satu manfaat perkembangan teknologi dan informasi adalah penggunaan komputer yang dapat mengakomodasi peserta didik yang sulit menerima pelajaran, karena dapat memberikan suasana yang lebih efektif secara individual, tidak pernah lupa, tidak pernah bosan, sangat sabar dalam menjalankan instruksi seperti yang terdapat dalam program (Nandya Hafsah, 2016).

Kurikulum 2013 memiliki karakteristik menggunakan pendekatan ilmiah serta merekomendasikan pengalaman penuh potensi peserta didik dan membangkitkan motivasi (Agus, 2019). Pendidik dalam sistem pembelajaran dituntut untuk bisa menjadi inovatif dan kreatif dalam memilih media pembelajaran yang sesuai dengan materi yang disampaikan guna meningkatkan mutu pendidikan (Pahrudin, 2019). Teknologi informasi dan komunikasi merupakan salah satu media interaktif yang digunakan dalam interaksi jarak jauh, sehingga TIK dapat memfasilitasi pembelajaran pada masa perkembangan teknologi dan komunikasi yang semakin pesat. E-modul merupakan salah satu media pembelajaran yang dapat dimanfaatkan pada perkembangan teknologi sekarang ini, dimana hanya terdapat perbedaan cara membacanya saja jika dibandingkan dengan modul cetak (Ummah et al., 2018). Karakteristik E-modul sama halnya dengan modul cetak, karena karakteristik modul cetak dapat diterapkan untuk pembuatan E-modul (Priatna et al., 2017). Perbedaan modul cetak dan E-modul hanya terlihat secara fisik, sedangkan komponen yang terdapat di dalamnya sama dengan modul cetak pada umumnya (Erlan Simarta, Gede Santyadiputra, 2017).

Smartphone merupakan dampak perkembangan teknologi yang dilengkapi dengan sistem operasi android. Android merupakan sebuah sistem yang menjembatani antara Emodul dengan pengguna, sehingga pengguna dapat menjalankan aplikasi yang tersedia (Wiranda \& Adri, 2019). Android dapat dijadikan penunjang pembelajaran bagi peserta didik sebagai pemanfaatan teknologi di bidang pendidikan (Haka, Nukhbatul Bidayati, 2018).

Pembelajaran menggunakan E-modul android merupakan upaya agar pembelajaran dapat berlangsung secara efektif, efisien, dan memiliki daya tarik tinggi khususnya pada pembelajaran biologi (Tety Yunara Megadani, 2018). Oleh karena itu E-modul android sebaiknya dikembangkan dengan berbagai pendekatan. Metakognisi sangat dibutuhkan untuk membantu peserta didik menjadi seseorang yang dapat berpikir kritis, terutama pada tingkat sekolah menengah. Metakognisi perlu diintegrasikan dalam pembelajaran agar peserta didik dapat berlatih berpikir kritis serta dapat mengontrol dirinya dalam belajar. 
Metakognisi merupakan pengetahuan tentang memori, yang mencakup pengetahuan umum tentang memori, seperti mengetahui bahwa tes pengalaman lebih mudah dari tes mengingat serta tentang kemampuan murid untuk memonitor apakah dirinya sudah cukup dalam belajar untuk menghadapi serangkaian ujian (Santrock, 2004). Kemampuan metakognisi dapat dikembangkan dengan menerapkan indikator metakognisi, yaitu pengetahuan deklaratif, pengetahuan prosedural, dan pengetahuan kondisional (Prayogi et al., 2019). Perkembangan metakognisi dapat diupayakan dengan cara peserta didik dituntut untuk mengobservasi tentang apa yang mereka ketahui dan kerjakan untuk merefleksi tentang apa yang dia observasi (Rahman, 2018).

Kebutuhan dalam proses belajar sekarang ini adalah media pembelajaran berbasis teknologi yang mampu mengembangakan kemampuan metakognisi untuk meningkatkan daya pikir peserta didik dan kemampuan belajarnya (Setiawan \& Susilo, 2015). Akan tetapi, dari hasil pra survey yang dilakukan oleh peneliti di SMAN 1 Jati Agung, diketahui bahwa media pembelajaran yang digunakan hanya berupa buku yang dipinjam dari perpustakan. Hal tersebut menjadi hambatan bagi peserta didik untuk belajar secara mandiri karena terbatasnya jumlah buku yang disediakan. Pendidik dan peserta didik mengharapkan adanya media pembelajaran yang dapat membantu dalam proses belajar.

Berdasarkan hasil pra survey, peneliti akan melalukan penelitian dan pengembangan terhadap media pembelajaran yang dibutuhkan. Peneliti akan mengembangkan media pembelajaran berupa E-modul android berbasis metakognisi yang sesuai dengan kebutuhan peserta didik. Penelitian yang dilakukan bertujuan untuk menghasilkan E-Modul android berbasis metakognisi yang layak digunakan dalam pembelajaran biologi materi bioteknologi kelas XII. E-Modul android berbasis metakognisi yang dikembangkan bersifat praktis, serta dapat digunakan secara offline dan online untuk memberikan komentar terkait dengan kesulitan dalam memahami materi pelajaran.

Penelitian sebelumnya tentang pengembangan modul berbasis metakognisi sudah pernah dilakukan antara lain oleh Telaumbanua (2018); Zulfikar \& Tamrin (2019); dan Yusra et al. (2019). Namun modul tersebut belum dalam bentuk elektronik (e-modul) sehingga kesulitan diterapkan dalam pembelajaran daring sebagai dampak pandemi Covid-19 pada masa kini (2021). Demikian pula penelitian tentang pengembangan e-modul dalam pembelajaran biologi sudah pernah dilakukan antara lain Nova et al. (2021); Devie et al. (2020); Pratama et al. (2018); dan Syafriah (2017). Namun e-modul yang dikembangkan belum berbasis metakognisi. Penelitian ini memenuhi kebutuhan dalam pembelajaran di masa pandemi Covid 19, dimana menggunakan e-modul sehingga dapat diimplementasikan dalam pembelajaran daring dan berbasis metakognisi sebagai capaian yang penting dimiliki oleh peserta didik. Penelitian ini bertujuan mengembangkan e-modul android berbasis metakognisi serta menguji validitas, kepraktisan, dan efektivitasnya.

\section{METODE}

Penelitian ini merupakan jenis penelitian dan pengembangan (Research and Development), dengan sepuluh langkah pengembangan Borg and Gall (Borg, 2003). Langkah pengembangan tersebut disederhanakan menjadi tujuh langkah tanpa mengurangi nilai pengembangan itu sendiri (Sanjaya, 2013). Langkah pengembangan disederhanakan karena pada tahap ketujuh pengembangan telah mencapai tujuan pengembangan dari penelitian ini. Tujuh langkah pengembangan tersebut adalah studi pendahuluan, perencanaan desain, 
pengembangan desain, uji coba terbatas, revisi hasil uji coba terbatas, uji coba produk secara skala luas, dan revisi hasil uji coba skala luas.

Penelitian dan pengembangan dilakukan di SMAN 1 Jati Agung terhadap peserta didik kelas XII MIA. Sampel penelitian ini adalah 10 peserta didik untuk uji coba skala terbatas dan 30 peserta didik untuk uji coba skala luas. Pengambilan data dilakukan melalui observasi, dokumentasi, dan dari hasil angket. Angket digunakan untuk mendapatkan penilaian atas kelayakan E-modul android berbasis metakognisi dari para ahli media, bahasa, dan materi. Selain itu, angket juga digunakan untuk mengetahui respon peserta didik dan pendidik terhadap E-modul android berbasis metakognisi.

Data hasil penelitian dihitung menggunakan rumus sebagai berikut:

Rumus perhitungan tiap butir pernyataan

$\mathrm{P}=\frac{\text { jumlah skor hasil pengumpulan }}{\text { jumlah skor maksimal }}$ X $100 \%$

Keterangan:

$\mathrm{P} \quad=$ Persentase kelayakan

Rumus menghitung hasil rata-rata persentase angket

$\mathrm{P}=\frac{\sum \mathrm{P}}{\mathrm{n}}$

Keterangan:

$\mathrm{P} \quad=$ Persentase rata-rata

$\sum \mathrm{P} \quad=$ Jumlah Persentase

$\mathrm{N} \quad=$ Jumlah Item Angket

Rumus perhitungan lembar angket respon peserta didik dan pendidik

$\mathrm{P}=\frac{\mathrm{s}}{\mathrm{n}} \times 100 \%$

Keterangan:

$\mathrm{P} \quad=$ Persentase

$\mathrm{S} \quad=$ Jumlah jawaban responden dalam angket

$\mathrm{N} \quad=$ Jumlah nilai ideal dalam angket

\section{HASIL DAN PEMBAHASAN}

Hasil penelitian ini adalah E-modul android berbasis metakognisi yang dikembangkan berdasarkan tujuh langkah pengembangan menurut Borg and Gall. Tujuh langkah pengembangan tersebut adalah sebagai berikut:

\section{Studi Pendahuluan}

Studi pendahuluan terdiri dari dua kegiatan, yaitu studi lapangan dan studi literatur. Studi lapangan dilakukan dengan menggunakan wawancara dan angket analisis kebutuhan. Berdasarkan data angket pernyataan yang disebarkan kepada 30 peserta didik kelas VI dapat diketahui bahwa:

Table 1. Data Angket Pernyataan Kebutuhan Peserat Didik

\begin{tabular}{lc}
\hline \multicolumn{1}{c}{ Aspek } & Jumlah Peserta didik \\
\hline Kesulitan belajar biologi & 25 \\
Kurangnya media pembelajaran biologi & 28 \\
Kebutuhan media pembelajaran yang efisien & 30 \\
Kepemilikan smartphone android & 30 \\
Penggunaan android dalam belajar & 8 \\
\hline
\end{tabular}

Studi literatur yang merupakan proses pengumpulan informasi berbentuk konsep-konsep yang mendukung penelitian pengembangan E-modul android berbasis metakognisi sebagai 
media pembelajaran biologi peserta didik kelas XII. Berdasarkan kajian peneliti terdahulu, dapat diketahui bahwa perkembangan teknologi, informasi, dan komunikasi dapat bermanfaat terhadap dunia pendidikan sekarang ini (Purwaningtyas \& Hariyadi, 2017).

Perencanaan (planning)

Perencanaan penelitian ini dilakukan agar pengembangan E-modul android berbasis metakognisi dapat berjalan dengan sistemais dan terencana dengan baik. E-modul android akan dikembangkan dengan program komputer Integrated Development Enviroment (IDE) android studio. E-modul android yang dikembangkan berisi menu kompetensi, materi, video, evaluasi, kegiatan biologi, glosarium, pesan, profil, dan daftar pustaka. E-modul android akan diuji kelayakanya oleh 6 ahli, yaitu 2 ahli media, 2 ahli bahasa, dan 2 ahli materi, serta peserta didik kelas XII dan guru biologi kelas XII.

\section{Pengembangan Desain (Develop Prelimiery Form of Product)}

E-modul android dikembangkan dengan program komputer Integrated Development Enviroment (IDE) android studio. E-modul android dapat diinstal pada android tipe 4.4, memiliki kapasitas $60 \mathrm{Mb}$, dan dapat diperoleh dengan link yang dibagikan serta dengan menggunakan aplikasi shreit dan Bluetooth. E-modul android berbasis metakognisi dapat digunakan oleh penggunaya baik secara online maupun offline. E-modul android berbasis metakognisi berisi materi bioteknologi yang telah sesuai dengan Kompetensi Inti (KI), Kompetensi Dasar (KD), dan Indikator. Desain E-modul android berbasis metakognisi untuk lebih jelasnya dapat dilihat pada gambaran-gambaran awal produk berikut ini: 


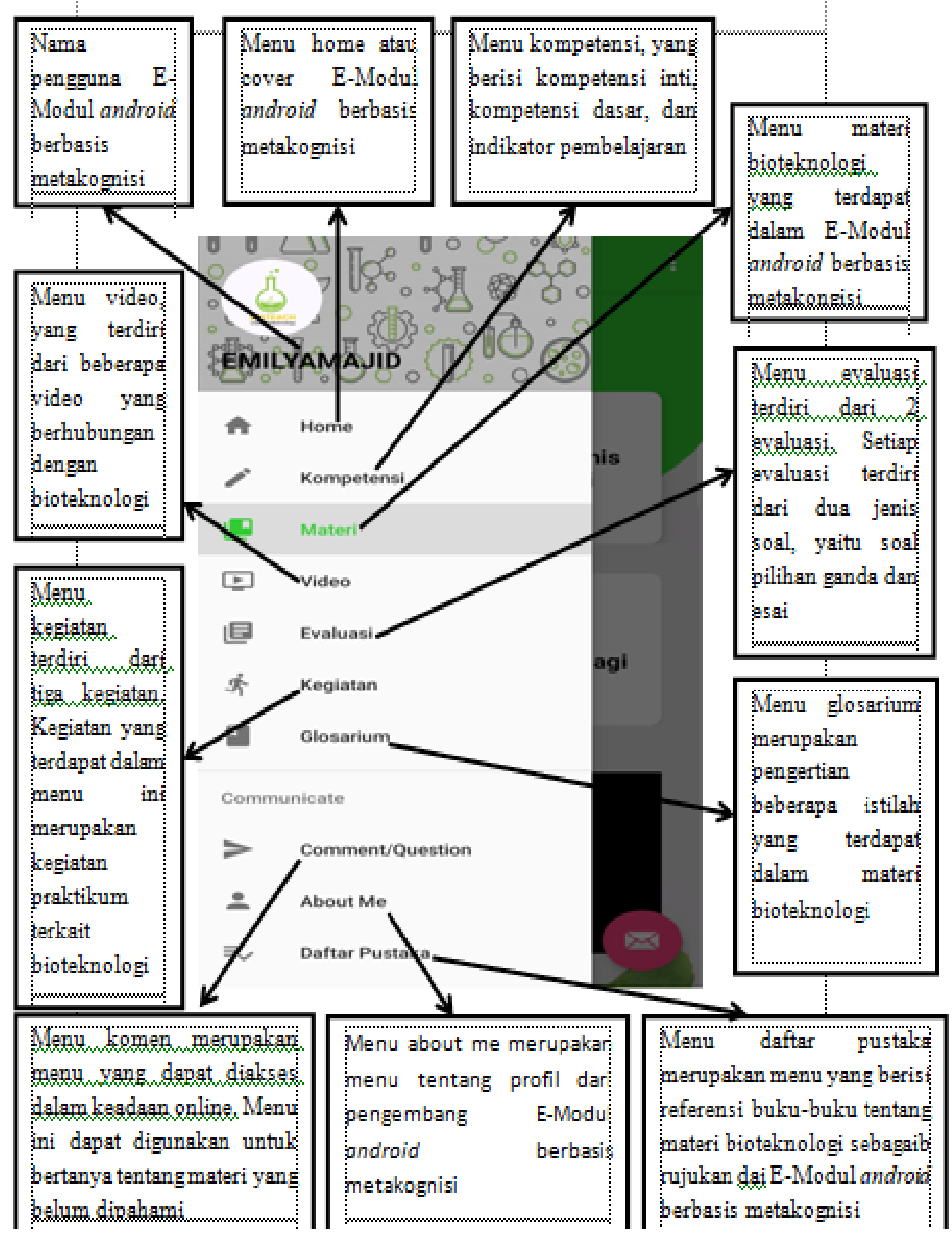

Gambar 1. Tampilan menu home 


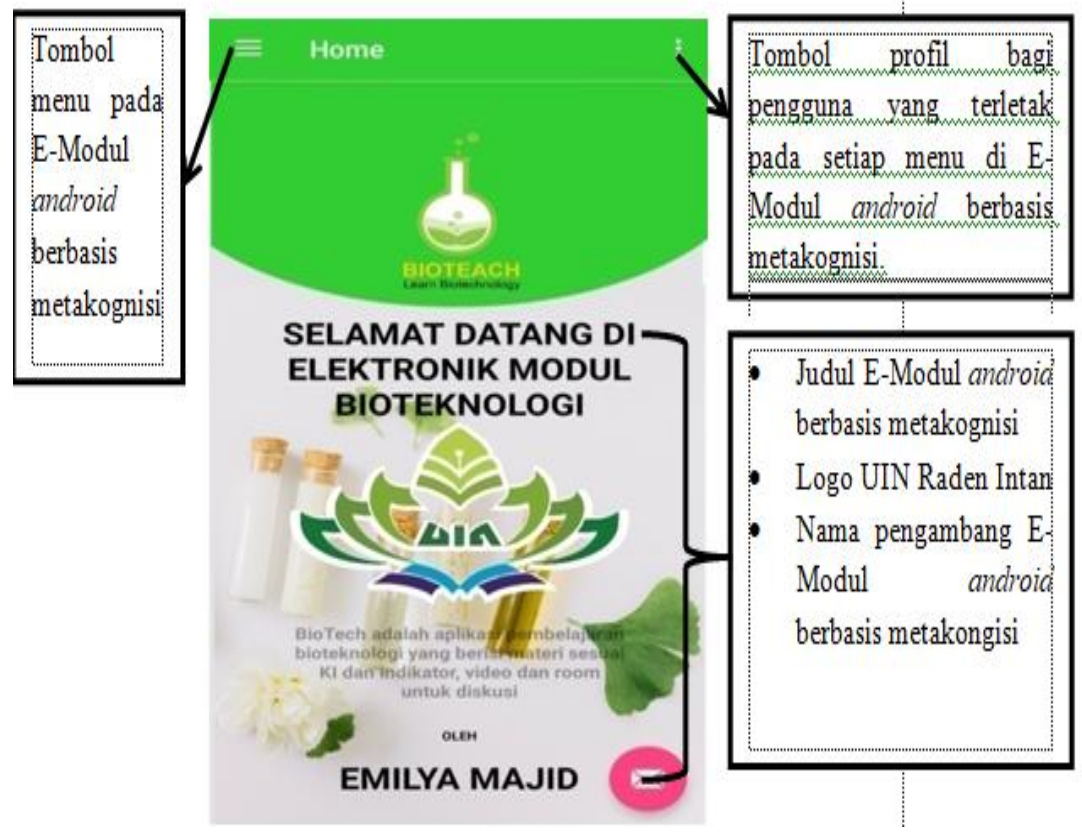

Gambar 2. Tampilan halaman

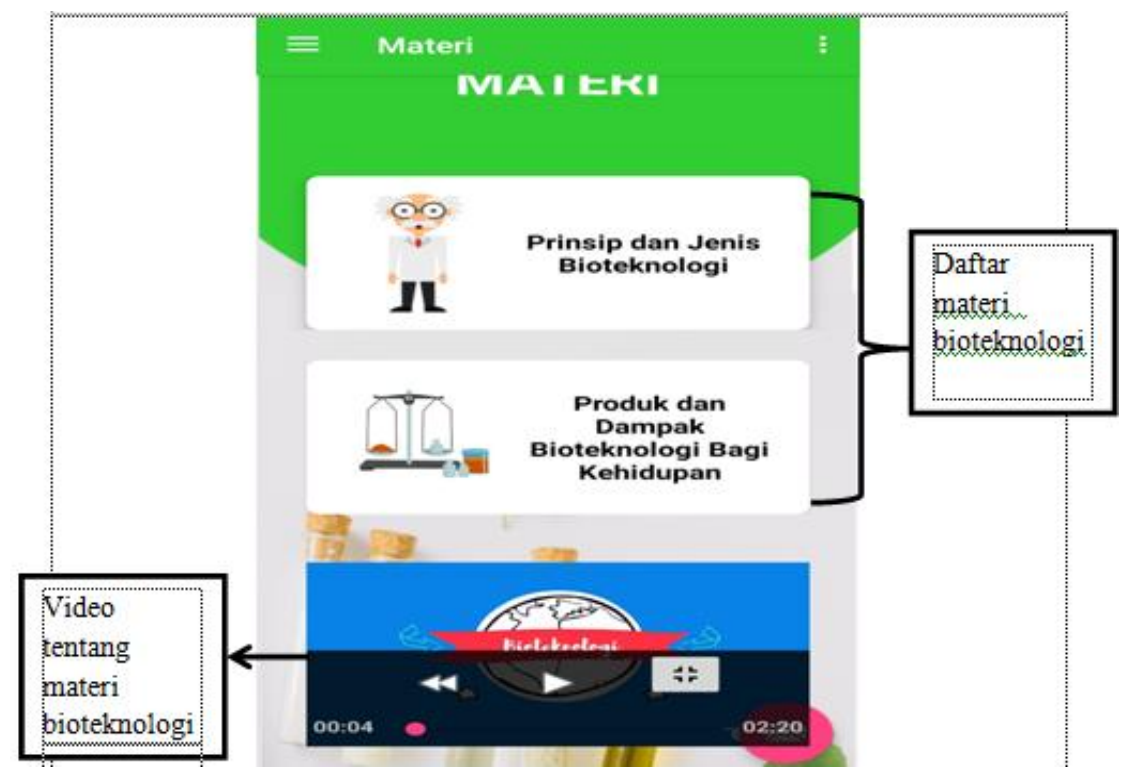

Gambar 3. Tampilan menu 


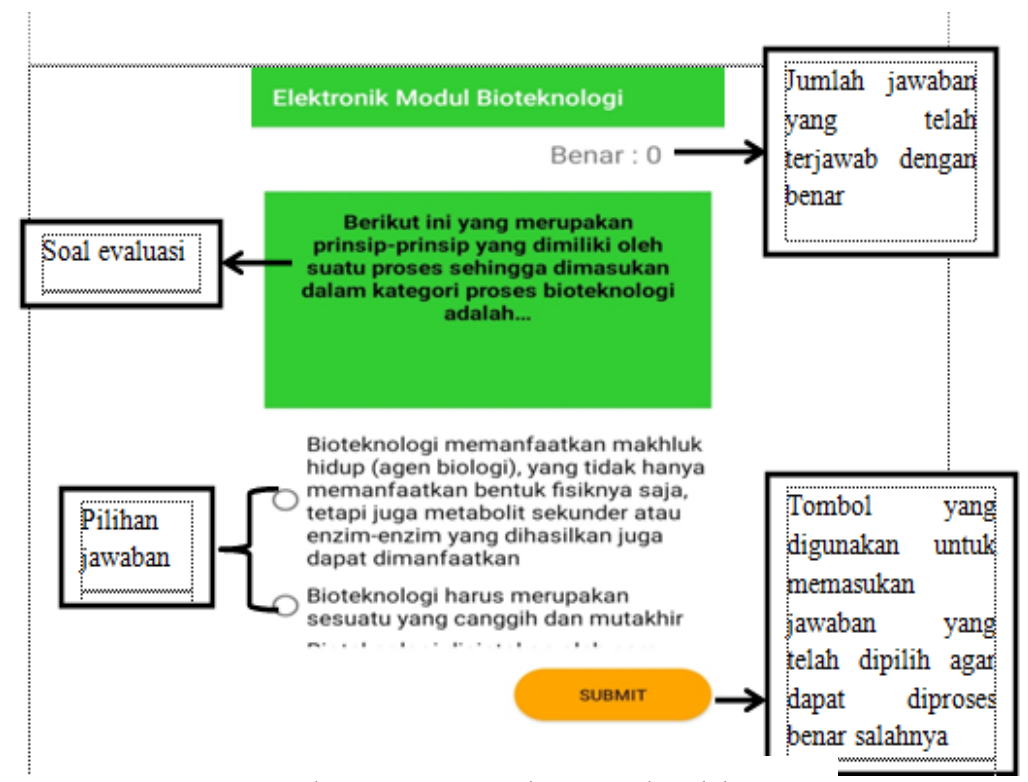

Gambar 4. Tampilan soal pilihan

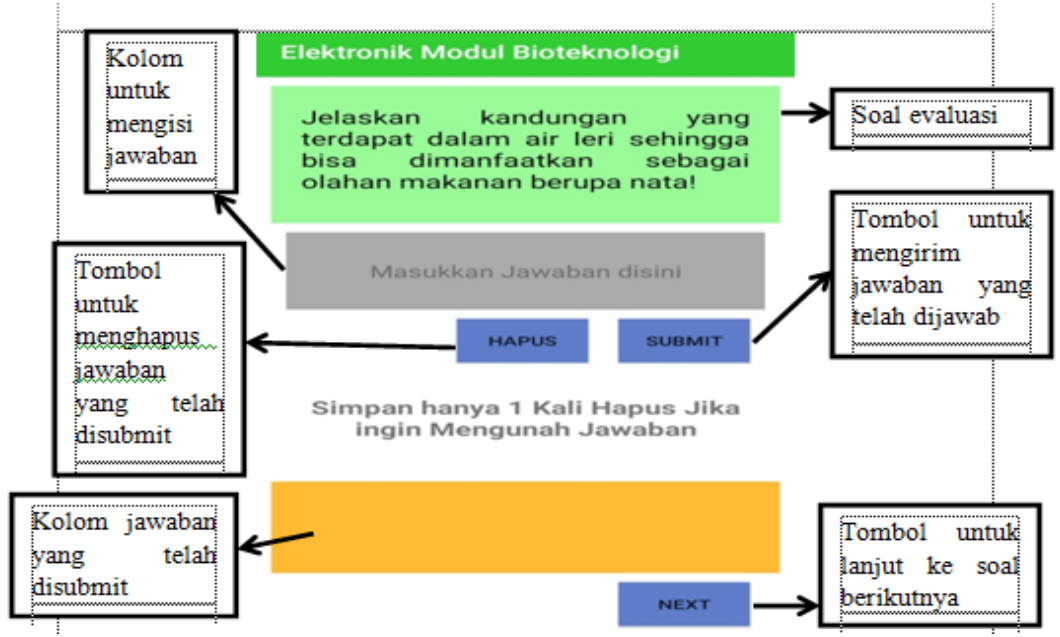

Gambar 5. Tampilan soal esai

\section{Uji Coba Pendahuluan atau Terbatas (Preliminary Field Testing)}

Uji coba pedahuluan dilakukan dengan menilai produk yang dikembangkan melalui validasi oleh para ahli. Validasi dilakukan untuk melihat kelayakan produk yang dikembangkan. Validasi dilakukan oleh tiga ahli, yaitu ahli media, ahli bahasa, dan ahli materi. Validasi para ahli juga dilakukan oleh para peneliti lainya dalam pengembangan produk, seperti yang dilakukan oleh Ana Ma'rifatun yang melakukan kegiatan validasi sebelum uji coba produk secara luas (Nurdiana et al., 2017). Berdasarkan data hasil validasi, diketahui bahwa E-modul android berbasis metakognisi layak untuk diuji cobakan secara luas. Hal tersebut dapat dilihat dalam diagram persentase kelayakan sebagai berikut: 


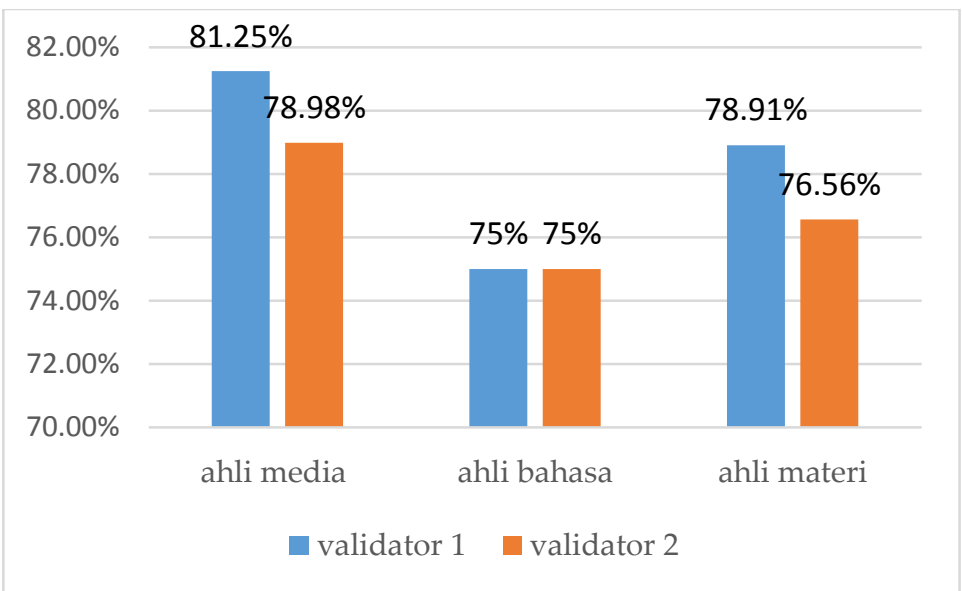

Gambar 7. Diagram kelayakan E-modul android berdasarkan validasi para ahli

Produk E-modul android berbasis metakognisi dinyatakan layak atau tidak melalui Tabel 2.

Tabel 2. Kriteria kelayakan produk

\begin{tabular}{|c|c|}
\hline Skor Persentase ( \% ) & Criteria \\
\hline $0-25 \%$ & Tidak Layak \\
\hline$>25-50 \%$ & Kurang Layak \\
\hline$>50-75 \%$ & Layak \\
\hline$>75-100 \%$ & Sangat Layak \\
\hline
\end{tabular}

(Sumber: Suharsimi Arikunto, 2008).

\section{Revisi Hasil Uji Coba Lapangan terbatas (Main Product Revision)}

Produk yang telah divalidasi direvisi sesuai dengan saran dari para ahli. Saran yang didapatkan pada validasi E-modul android berbasis metakognisi ditunjukkan pada Tabel 3.

Tabel 3. Saran dari para ahli terhadap E-modul android berbasis metakognisi

\begin{tabular}{cl}
\hline Validasi & \multicolumn{1}{c}{ Saran } \\
\hline Ahli Media I & Tidak ada \\
Ahli Media II & $\begin{array}{l}\text { 1. Warna background jangan memakai warna hijau } \\
\text { stabilo, karena terlalu terang }\end{array}$ \\
& $\begin{array}{l}\text { 2. Jenis font masih kaku } \\
\text { 3. Jarak, spasi belum konsisten }\end{array}$ \\
Ahli Materi I & $\begin{array}{l}\text { 1. Judul modul jangan dibalik "Modul Elektronik" } \\
\text { 2. Soal-soal evaluasinya perlui ditingkatkan jenjang } \\
\text { kognitifnya }\end{array}$ \\
Ahli Materi II & Penulisan dan pembuatan kalimat diperbaiki \\
\end{tabular}

(sumber: Data penelitian validasi produk, 2020)

Berdasarkan saran dari para ahli, dapat diketahui bahwa E-modul android masih memiliki beberapa kekurangan baik dari media yang ditampilkan maupun penulisan materi yang disampiakan. Saran yang diberikan oleh validator dijadikan acuan untuk memperbaiki Emodul android agar layak digunakan oleh peserta didik dan pendidik dalam pembelajaran biologi. E-modul android diperbaiki dengan merubah warna background, merubah jenis font, serta memperbaiki spasi yang digunakan. E-modul android juga telah diperbaiki dalam segi materi, baik dalam penyajian soal evaluasi yang ditingkatkan jenjang kognitifnya serta perbaikan dalam pembuatan kalimat dalam menjelaskan materi. Setelah dilakukan revisi 
berdasarkan saran para ahli, E-modul android telah layak diujicobakan kepada peserta didik dan pendidik.

\section{Uji Coba Produk Secara Lebih Luas (Main Field Testing)}

Uji coba produk secara luas dilakukan melalui dua tahap, yaitu uji coba terbatas dengan 10 peserta didik dan uji coba skala luas dengan 30 peserta didik. Peserat didik sebagai responden diambil dengan teknik purposive sampling dengan mempertimbangankan kepemilikan smartphone yang sesuai dengan spesifikasi android yang digunakan pada $E$ modul. Uji coba penelitan di SMAN 1 Jati Agung, dilakukan secara online melalui group WhatsApp. Hal tersebut karena adanya pandemi Covid 19 yang masih menjadi wabah bagi masyarakat Indonesia. Wabah ini tidak memungkinkan untuk adanya penelitian secara langsung karena peraturan dari pemerintah yang mengharuskan peserta didik serta para guru untuk bekerja dari rumah dan belajar dari rumah. Penggunaan WhatsApp pada pembelajaran daring ini banyak dilakukan oleh para pendidik atau dosen (Gunawan \& Fathoroni, 2020). Berdasarkan hasil uji coba secara luas, diketahui bahwa uji coba yang dilakukan dalam skala terbatas dengan menyajikan aspek media, penyajian materi, serta kebahasaan, menyatakan bahwa produk E-modul android berbasis metakognisi sangat layak sebagai media pembelajaran.

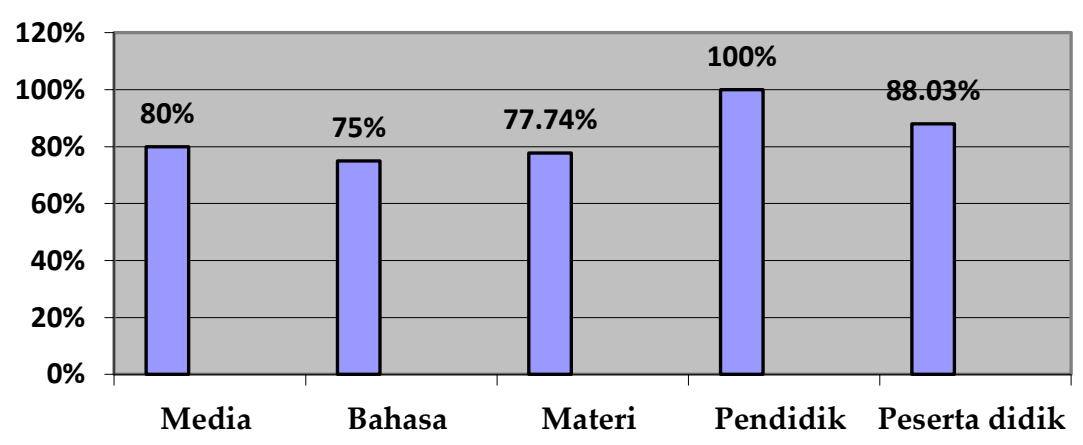

Gambar 8. Persentase kelayakan produk dari aspek media, bahasa, materi, serta dari respon pendidik dan peserta didik

Penelitian yang dilakukan secara online memiliki beberapa kendala dalam pemakaian produk E-modul android, yaitu terhambatnya pengiriman link E-modul android karena buruknya jaringan, serta keterbatasan paket data internet peserta didik. Selain itu, peserta didik sulit memahami dalam menjawab soal esay karena terbatasnya sarana dalam berkomunikasi untuk menjelaskan cara penggunaan produk E-modul android.

\section{Revisi Hasil Uji Coba Skala Luas (Product revision)}

Berdasarkan hasil uji coba skala besar yang meliputi ujicoba skala terbatas dan uji coba skala luas dapat diketahui bahwa para peserta didik memberikan penilaian sangat layak untuk produk E-modul android yang telah dikembangkan. Penelitian telah dilakukan sesuai dengan prosedur langkah penelitian dan pengembangan yang digunakan, meskipun dilakukan secara online terkait dengan kondisi pandemi sekarang ini. Pada keadaan pandemi sekarang ini, dimana pembelajaran di kelas digantikan dengan pembelajaran daring atau pembelajaran secara online, sangat dibutukan kecanggihan teknologi untuk menunjang keadaan tersebut. E-modul android merupakan sebuah aplikasi yang dapat digunakan oleh 
peserta didik sebagaia media pembelajaran secara online pada masa pandemi ini. Produk Emodul android yang telah dikembangkan ini memiliki banyak keunggulan. E-modul android berisikan materi bioteknologi yang dirancang sesuai dengan indikator metakognisi yaitu pengetahuan deklaratif, pengetahuan prosedural, pengetahuan kondisional serta langkah metakognisi yaitu perencanaan, pelaksanaan, dan evaluasi (Lidia et al., 2018). E-modul android juga dilengkapi dengan manu komentar yang dapat diakses dengan menggunakan jaringan internet atau secara online.

E-modul android disusun berdasakan indikator metakognisi karena metakognisi mengacu pada paham seseorang pada pengetahuanya terhadap kognitif, serta bagaimana mengaturnya (Nur \& Rusilowati, 2019). Selain memiliki kelebihan seperti yang telah dijelaskan, E-modul android berbasis metakognisi juga memiliki kelemahan. Kelemahan dari produk pengembangan ini adalah hanya dapat digunakan di smartphone android. Kapasitas yang dibutuhkan untuk dapat menggunaan E-modul android cukup besar. Selain itu pada produk ini penyajian materi hanya dibatasi untuk materi bioteknologi kelas XII. Pendidik menambahkan bahwasanya akan lebih baik jika produk E-modul android dikembangkan lagi sehingga dapat mencakup materi satu semester.

\section{SIMPULAN}

Pengembangan e-modul android berbasis metakognisi berdasarkan analisis kebutuhan diperoleh hasil yang valid, praktis, dan efektif, sehingga modul ini dapat direkomendasikan dalam pembelajaran biologi. E-modul android berbasis metakognisi dapat diinstal pada android tipe 4.4, memiliki kapasitas $60 \mathrm{Mb}$, dapat diperoleh dengan link yang dibagikan dengan menggunakan aplikasi shreit dan Bluetooth, serta dapat digunakan dalam keadaan online atau offline. Berdasarkan penilaian para ahli, E-modul android layak diujicobakan di lapangan. Respon peserta didik dan pendidik terhadap E-modul andorid berbasis metakognisi sangat antusias. persentase kelayakan sebesar $88,03 \%$ dan $100 \%$ dari pendidik dengan kriteria sangat layak.

\section{DAFTAR PUSTAKA}

[1] Devie, D. N., Gusfarenie, D., \& Safita, R. (2020). Pengembangan e-modul biologi umum berbasis konstruktivisme menggunakan 3D Pageflip. Jurnal Kependidikan Betara, 1(4), 152-162.

[2] Simarmata, E. A., Santyadiputra, G. S., ST, M. C., \& Divayana, D. G. H. (2017). Pengembangan e-modul berbasis model pembelajaran project based learning pada mata pelajaran pemrograman desktop kelas XI rekayasa perangkat lunak di SMK Negeri 2 Tabanan. KARMAPATI (Kumpulan Artikel Mahasiswa Pendidikan Teknik Informatika), 6(1), 93-102.

[3] Fatoni, A., \& Rendra, D. B. (2014). Perancangan prototype sistem kendali lampu menggunakan handphone android berbasis arduino. PROSISKO: Jurnal Pengembangan Riset dan Observasi Sistem Komputer, 1.

[4] Fazriyah, N. (2016). Pengembangan kemampuan berpikirkritis, kreatifitas, komunikasi, dan kolaborasi dalam pembelajaran abad 21, Prosiding Seminar Jurnal Pendidikan Dasar, 1: 285-290.

[5] Gall, M. D., Gall, J. P., \& Borg, W. R. (2014). Applying educational research: How to read, do, and use research to solve problems of practice. Pearson Higher Ed.

[6] Gunawan, G., Suranti, N. M. Y., \& Fathoroni, F. (2020). Variations of models and learning platforms for prospective teachers during the COVID-19 pandemic period. Indonesian Journal of Teacher Education, 1(2), 61-70.

[7] Hidayat, Y. N., Wardono, W., \& Rusilowati, A. (2019, February). Analisis kemampuan literasi matematika ditinjau dari metakognisi siswa dalam pembelajaran synectics berbantuan schoology. In PRISMA, Prosiding Seminar Nasional Matematika (Vol. 2, pp. 911-916). 
[8] Hafsah, N. R., Rohendi, D., \& Purnawan, P. (2016). Penerapan media pembelajaran modul elektronik untuk meningkatkan hasil belajar siswa pada mata pelajaran teknologi mekanik. Journal of Mechanical Engineering Education, 3(1), 106-112.

[9] Haka, N. B. (2020). Pengembangan komik manga biologi berbasis android untuk peserta didik kelas XI di tingkat SMA/MA. Journal Of Biology Education, 1(1), 17-32.

[10] Haka, N. B., Makrupah, S., \& Anggoro, B. S. (2020). Pengembangan website online berbasis blended learning untuk meningkatkan penguasaan konsep mata pelajaran IPA. Jurnal Bioterdidik, 8(1): 66-76. https://doi.org/10.23960/jbt.v8.i1.08

[11] Lidia, R., Sarwi, S., \& Nugroho, S. E. (2018). Pengaruh model pembelajaran problem based learning berbantuan modul terhadap kemampuan metakognitif siswa. UPEJ Unnes Physics Education Journal, 7(2), 104-111.

[12] Muhali, M., Prayogi, S., Asy'ari, M., Hunaepi, H., Sukarma, I. K. S. K., Mirawati, B., ... \& Fitriani, H. (2019). Pelatihan guru MIPA MAN 3 Lombok Tengah dalam menyusun perangkat pembelajaran yang melatihkan kemampuan metakognisi siswa. BAKTIMAS: Jurnal Pengabdian pada Masyarakat, 1(1), 49-60.

[13] Nova, N., Degeng, I. N. S., \& Sulton, S. (2021). Pengembangan e-modul pembelajaran agama kristen menggunakan scaffolding untuk meningkatkan kemampuan metakognitif komunitas remaja kristen sumba. Edcomtech Jurnal Kajian Teknologi Pendidikan, 6(1), 69-79.

[14] Nurdiana, A. M. R., Sutarman, S., \& Widjianto, W. (2019). Pengembangan media modul elektronik berbasis android pada pokok bahasan suhu dan kalor. Jurnal Riset Pendidikan Fisika, 2(1), 30-35.

[15] Pahrudin, A., Nur, A., Syamsul, H., \& Nita, A. (2020). The effects of the ECIRR learning model on mathematical reasoning ability in the curriculum perspective 2013: Integration on student learning motivation. European Journal of Educational Research, 9(2), 675-684.

[16] Pahrudin, M. P. (2019). Development of islamic value-based picture in biology learning with the ISI-ARE model. Tadris: Jurnal Keguruan dan Ilmu Tarbiyah, 4(2), 237-248.

[17] Permani, A., \& Priyanto, P. (2019). Pengembangan modul elektronik pemrograman berorientasi objek untuk siswa kelas XI rekayasa perangkat lunak dengan model four-D. Elinvo (Electronics, Informatics, and Vocational Education), 4(1), 12-16.

[18] Pratama, M., Johari, A., \& Marzal, J. (2018). pengembangan e-modul biologi berbasis potensi daerah kerinci pada materi plantae dan animalia: Development of Biological E-Modules Based on Kerinci Resources for Plantae And Animalia Materials. Edu-Sains: Jurnal Pendidikan Matematika dan Ilmu Pengetahuan Alam, 7(2), 1-10.

[19] Priatna, I. K., Putrama, I. M., \& Divayana, D. G. H. (2017). Pengembangan e-modul berbasis model pembelajaran project based learning pada mata pelajaran videografi untuk siswa kelas X Desain Komunikasi Visual di SMK Negeri 1 Sukasada. Jurnal Nasional Pendidikan Teknik Informatika: JANAPATI, 6(1), 70-78.

[20] Purwaningtyas, P., Dwiyogo, W. D., \& Hariyadi, I. (2017). Pengembangan modul elektronik mata pelajaran pendidikan jasmani, olahraga, dan kesehatan kelas XI berbasis online dengan program Edmodo. Jurnal Pendidikan: Teori, Penelitian, dan Pengembangan, 2(1), 121-129.

[21] Rahman, A. (2018). Profil kemampuan berpikir kritis dan kemampuan metakognitif siswa berdasarkan jenis kelamin. Jurnal Pendidikan Biologi, 10(1), 28-43.

[22] Sanjaya, W. (2013). Penelitian Pendidikan Jenis, Metode, dan Prosedur. Jakarta: Kencana Pranamedia Group.

[23] Santrock, J.W. (2004). Psikologi Pendidikan Edisi Dua. Jakarta: Kencana Prenandamedia Group.

[24] Setiawan, D., \& Susilo, H. (2015, March). Peningkatan keterampilan metakognitif mahasiswa program Studi biologi melalui penerapan jurnal belajar dengan Strategi jigsaw dipadu PBL berbasis lesson study Pada matakuliah biologi umum. In Prosiding Seminar Nasional Pendidikan Biologi (Vol. 2009, pp. 359-369).

[25] Subarkah, A. N. Qolbi, F.S. Irwansyah, W. Darmalaksa, \& Mahmud. (2017). Developing emodul based on islamic values, The 2nd International Conference on Sosialogy Education, : 190-194. 
[26] Syafriah, U. (2017). Pengembangan e-modul pada mata pelajaran biologi materi pokok animalia invertebrata untuk siswa kelas X di SMA Negeri 1 Dawarblandong Kabupaten Mojokerto. Jurnal Mahasiswa Teknologi Pendidikan, 8(2).

[27] Telaumbanua, Y. N. (2018). Pengembangan modul matematika berbasis strategi metakognitif dalam meningkatkan kemampuan koneksi matematis siswa SMA. JURNAL EDUCATION AND DEVELOPMENT, 3(1), 98-98.

[28] Megadani, T. Y., Lukitasari, M., \& Yuhanna, W. L. (2018, November). Pengembangan modul biologi pada materi pertumbuhan dan perkembangan berbasis metakognisi. In Prosiding Seminar Nasional SIMBIOSIS (Vol. 3).

[29] Ummah, R., Suarsini, E., \& Lestari, S. R. (2018, February). Analisis kebutuhan pengembangan e-modul berbasis penelitian uji antimikroba pada matakuliah mikrobiologi. In Seminar Nasional Pendidikan IPA 2017 (Vol. 2).

[30] Wiranda, T., \& Adri, M. (2020). Rancang Bangun Aplikasi Modul Pembelajaran Teknologi WAN Berbasis Android. VoteTEKNIKA: Jurnal Vocational Teknik Elektronika dan Informatika, 7(4), 85-92.

[31] Yusra, A. A., Maris, I. M., \& Haris, V. (2019). Pengembangan modul prisma dan limas berbasis pendekatan metakognitif untuk kemampuan berpikir kreatif matematis siswa. PROCEEDING IAIN Batusangkar, 3(2), 76-87.

[32] Zulfikar, R. N., \& Tamrin, M. (2019). Pengembangan modul matematika dengan pendekatan metakognitif untuk memfasilitasi kemandirian belajar siswa SMK Muhammadiyah Kupang. ANARGYA: Jurnal Ilmiah Pendidikan Matematika, 2(2), 70-74. 